\title{
COMPLEMENT RECEPTOR 1 (CR1) ON ERYTHRO- CYTES OF PATIENTS WITH SYSTEMIC LUPUS ERYTHEMATOSUS
}

\author{
Tatsuo Kawaguchi, ${ }^{1, *}$ Eisuke YoKota, ${ }^{1, * *}$ Yoshiyuki Nrho, ${ }^{1}$ \\ and Takashi IMAmura ${ }^{2}$ \\ ${ }^{1}$ The First Department of Internal Medicine, Faculty of Medicine, \\ Kyushu University, Higashi-ku, Fukuoka 812, Japan \\ ${ }^{2}$ Department of Human Genetics, National Institute of Genetics, \\ Mishima 411, Japan
}

\begin{abstract}
Summary Ninety-five $(85 \%)$ of the 112 Japanese patients with systemic lupus erythematosus (SLE) were negative for the complement receptor 1 (CR1) activities on erythrocytes, while $770(91 \%)$ of the 847 normal subjects were positive for CR1, as determined by immune-adherence hemagglutination. Pedigree analyses of the normal population suggested that the phenotype of negative CR1 was determined by a autosomal recessive gene. Among 112 SLE patients, $73(65 \%)$ showed persistently negative CR1 during remission for over 26 months of follow-up, although the CR I levels did vary with the disease activity in 22 SLE patients. These results show that the relative risk for developing SLE in persons with negative CR1 is 19. CR1 activity appears to be an important genetic factor related the development of SLE.
\end{abstract}

Key Words complement receptor 1, systemic lupus erythematosus

\section{INTRODUCTION}

The pathogenesis of systemic lupus erythematosus (SLE) is apparently of multifactorial origin, including hereditary and environmental factors. A genetic predisposition to SLE has been suggested by the epidemiological studies of twins (Block et al., 1975) and by animal models of inbred mice (Hahn, 1987).

Receptors for the third and fourth components of the activated complement system (complement receptor 1, CR1) are present on erythrocytes, neutrophils,

Received July 12, 1988; revised version received September 30; Accepted October 3, 1988

* Present address: Department of Human Genetics, Medical Research Institute, Tokyo Medical and Dental University, 1-5-45 Yushima, Bunkyo-ku, Tokyo 113, Japan.

** Offprint requests to: Dr. Eisuke Yokota, The First Department of Internal Medicine, Faculty of Medicine, Kyushu University, 3-1-1 Maidashi, Higashi-ku, Fukuoka 812, Japan. 
monocytes, B lymphocytes, some T lymphocytes and renal podocytes (Fearon, 1980; Bianco and Nussenzweig, 1977; Ross, 1979; Wilson et al., 1982a; Gelfand et al., 1975; Kazatchkine et al., 1982). Although the number of CRl molecules expressed on each red cell is less than $1 \%$ of those on leukocytes, more than $90 \%$ of the total CRI on the surface of the peripheral blood cells are associated with red cells, because the mass of erythrocytes far exceeds that of leukocytes (Fearon, 1980). CR1 has a role in processing and clearance of microorganisms coated with $\mathrm{C} 3 \mathrm{~b} / \mathrm{C} 4 \mathrm{~b}$ as well as immune complexes (IC), and most of the IC in the circulation is bound on the surface of erythrocytes. Therefore, if the CRI on the erythrocytes is defective, free IC are not removed from the circulation and possibly cause tissue damage (Siegel et al., 1981; Cornacoff et al., 1983).

Miyakawa et al. (1981) found that levels of CRI on erythrocytes were low in patients with SLE. Because the low CRI levels were persistent in patients irrespective of the disease activity, and because they were observed frequently in family members, the defect would appear to be heritable. Wilson et al. (1982b) estimated the number of CR1 sites on erythrocytes, using a monospecific anti-CR1 antibody. They found that CR1 levels showed a trimodal distribution among the normal population. Thus, CRI expression was thought to be controlled by two allelic genes, designated high $(\mathrm{H})$ and low $(\mathrm{L})$, and expressed codominantly on the erythrocyte membranes.

Iida et al. (1982) noted an increase in CR1 levels on erythrocytes in 2 of the 4 patients with SLE and entering remission. Inada et al. (1982) showed an inverse correlation between CRI levels and the concentration of immune complexes in the circulation. Moreover, Holme et al. (1986) pointed out that numbers of CR1 were different in each of the two of identical twins with SLE. These reports suggested that the defective CRI was, at least in part, a reversibly changed and acquired condition rather than a genetically determined state.

We report here CR1 levels on erythrocytes from SLE patients and those of normal subjects. The objective of the study was to search for possible genetic factors associated with the development of SLE.

\section{PATIENTS AND METHODS}

Patients. We studied 112 Japanese patients with SLE, who had been admitted or who were seen in the clinic of the First Department of Medicine, Kyushu University. The diagnosis of SLE was made according to the revised criteria by American Rheumatism Association (ARA) (Tan et al., 1982). One hundred and sixty-two workers of a company in Fukuoka city and 685 residents in Yonaguni and Hateruma Islands, Okinawa Prefecture, served as the healthy controls. Family studies were performed for 59 members from the 19 families of probands having SLE and 146 members from the 25 families of normal control subjects.

Immune-Adherence Hemagglutination (IAHA). The CR1 levels were measured according to the method of IAHA, as described by Miyakawa et al. (1981). Human 
IgG was prepared from pooled sera by salt precipitation and chromatography on DEAE-cellulose and was stored at $-70^{\circ} \mathrm{C}$. A solution of IgG in phosphate-buffered saline $(10 \mathrm{mg} / \mathrm{ml})$ was heated at $65^{\circ} \mathrm{C}$ for $30 \mathrm{~min}$. After the precipitates had been removed by centrifugation at $15,000 \times g$ for $15 \mathrm{~min}$, the supernatant was used as the aggregated human $\gamma$-globulin (AHG). Serial two-fold dilutions of AHG starting from $100 \mu \mathrm{g} / \mathrm{ml}$ were prepared in a gelatin-veronal-buffer $\left(\mathrm{GVB}^{2+}\right)$ in a polystyrene U-bottom microtiter plate. Complement was prepared by dilution of guinea pig serum in $\mathrm{GVB}^{2+}$ containing $3 \mathrm{CH} 50$ units $/ \mathrm{ml}, 25 \mu 1$ of which was added to each well. The plate was incubated at $37^{\circ} \mathrm{C}$ for $45 \mathrm{~min}$. Thereafter, $25 \mu 1$ of dithiothreitol solution $(3 \mathrm{mg} / \mathrm{ml})$ was added to protect the generated $\mathrm{C} 3 \mathrm{~b}$ sites from decay (Mayumi et al., 1971). Subsequently, $25 \mu$ l of erythrocytes suspension $\left(2 \times 10^{8}\right.$ cells/ $\mathrm{ml}$ in EDTA-GVB) was transferred to each well and the plate was incubated at $24^{\circ} \mathrm{C}$ for further $60 \mathrm{~min}$. The pattern of hemagglutination was observed and the IAHA levels of erythrocytes were expressed by the highest dilution $\left(2^{N}\right)$ of $\mathrm{AHG}$ that induced hemagglutination.

\section{RESULTS}

\section{CRI levels of SLE patients and normal controls}

Figure 1 illustrates the distribution of IAHA titers of erythrocytes from the 112 SLE patients and the 847 normal controls. Seventy-three $(65 \%)$ SLE patients showed no detectable IAHA levels, 38 patients had titers ranging from $2^{4}$ to $2^{8}$, and 1 patient had a titer of $2^{11}$. In contrast to the SLE patients, IAHA titers showed a trimodal distribution in normal controls and only $77(9 \%)$ showed a negative IAHA. No overlaps between positive and negative groups were observed in either SLE patients or the normal controls.

\section{Family study of CRI levels in the normal population}

Among 77 individuals in the normal population with a negative CR1, 25 families were available for pedigree analyses and CR 1 levels on erythrocytes from 146 members were investigated by IAHA (Fig. 2). Forty (27\%) of the 146 members were negative for CR1 and more than two members had a negative CR1 in 8 families.

\section{CR1 levels of members of SLE families}

CR1 levels on erythrocytes from the 59 relatives of 19 SLE patients were assessed by IAHA. As shown in Fig. 3, clustering of negative CR 1 was observed in 9 families. Six $(33 \%)$ of 18 siblings tested had a negative CR1, thereby indicating that the frequency of negative CR1 is about 3 times higher in siblings of SLE patients than that in normal controls. In one family (Fig. 3B) all members of the proband tested so far have a negative CR1. Here a younger sister of the proband was found to have SLE. The mother showed no clinical symptoms of SLE but the laboratory data were positive for the LE-test, hypergammaglobulinemia as well as leukopenia. She therefore may have had a strong genetic potential to develop SLE. 

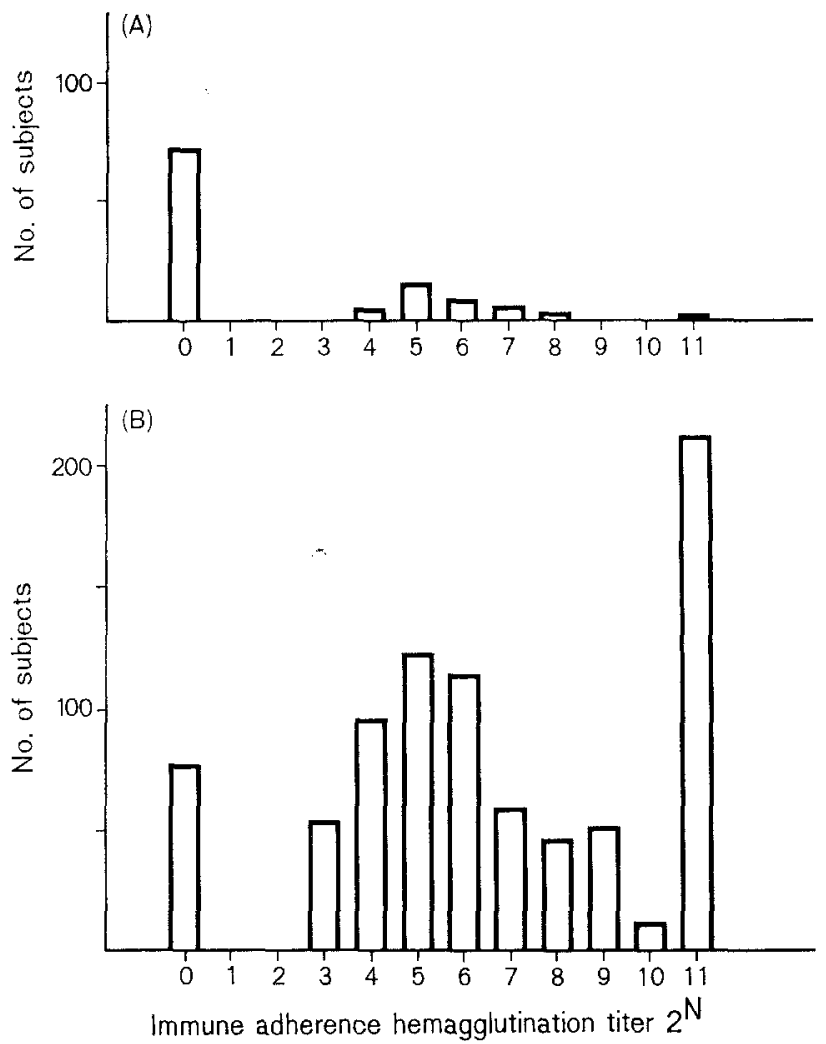

Fig. 1. Distribution of immune-adherence hemagglutination (IAHA) titers of erythrocytes from 112 patients with SLE (A) and 847 healthy controls (B).

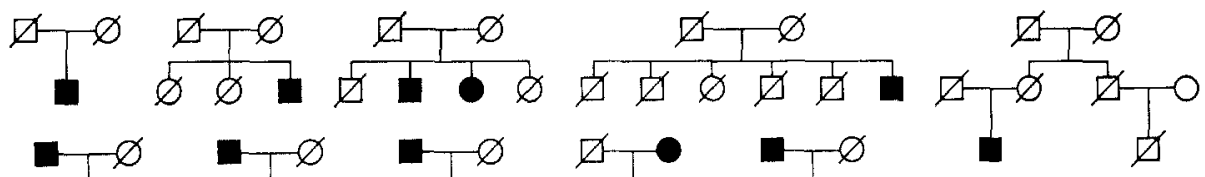<smiles></smiles><smiles>[13CH3][13CH3]</smiles><smiles>O[C@H]1[CH]O1</smiles><smiles>[R]C(C)C</smiles>

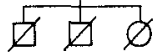
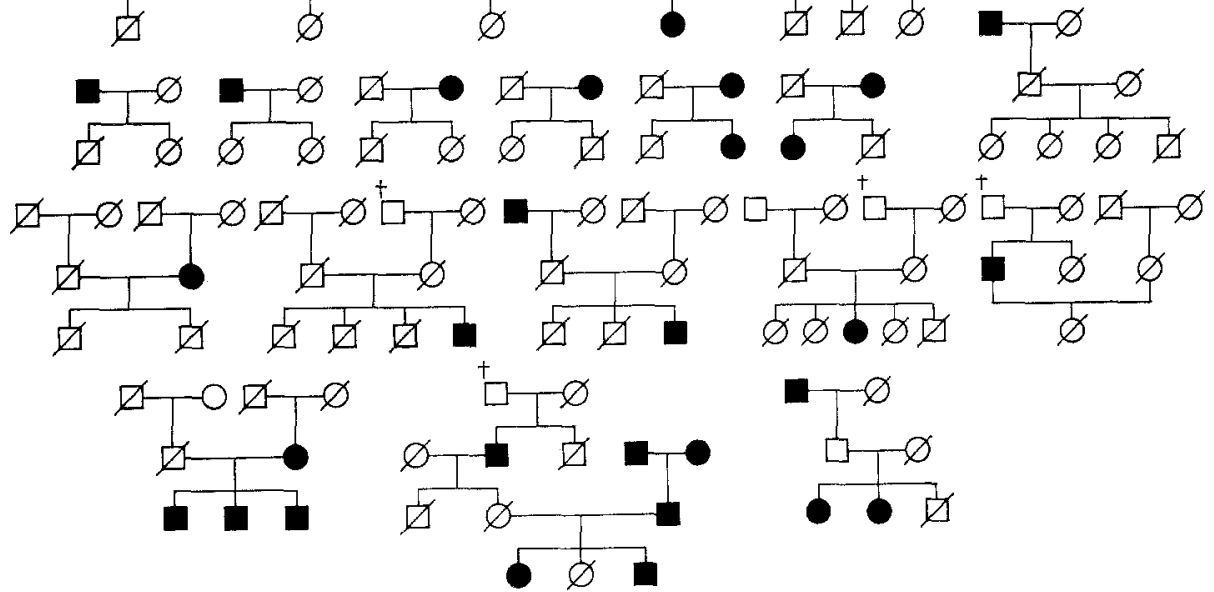

Fig. 2. CR1 levels in a normal population. Positive CR1, $\square \varnothing$; Negative CR1, 
(A)

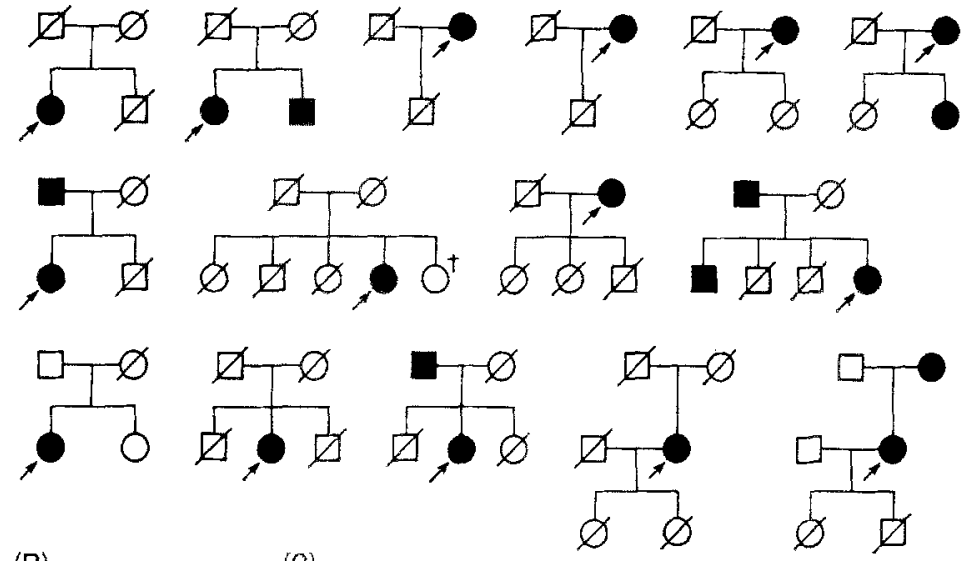

(B)

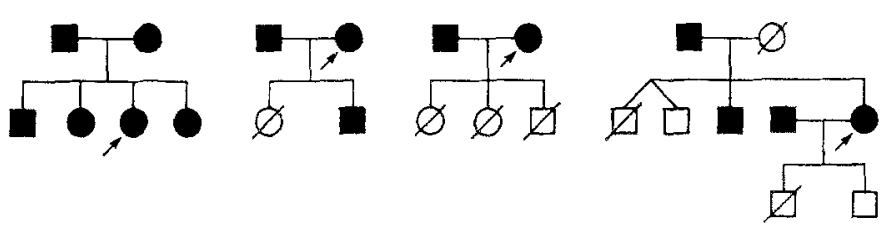

Fig. 3, CR1 levels in patients with SLE and in their relatives. Positive CR1, ØØ; Negative CR1, =

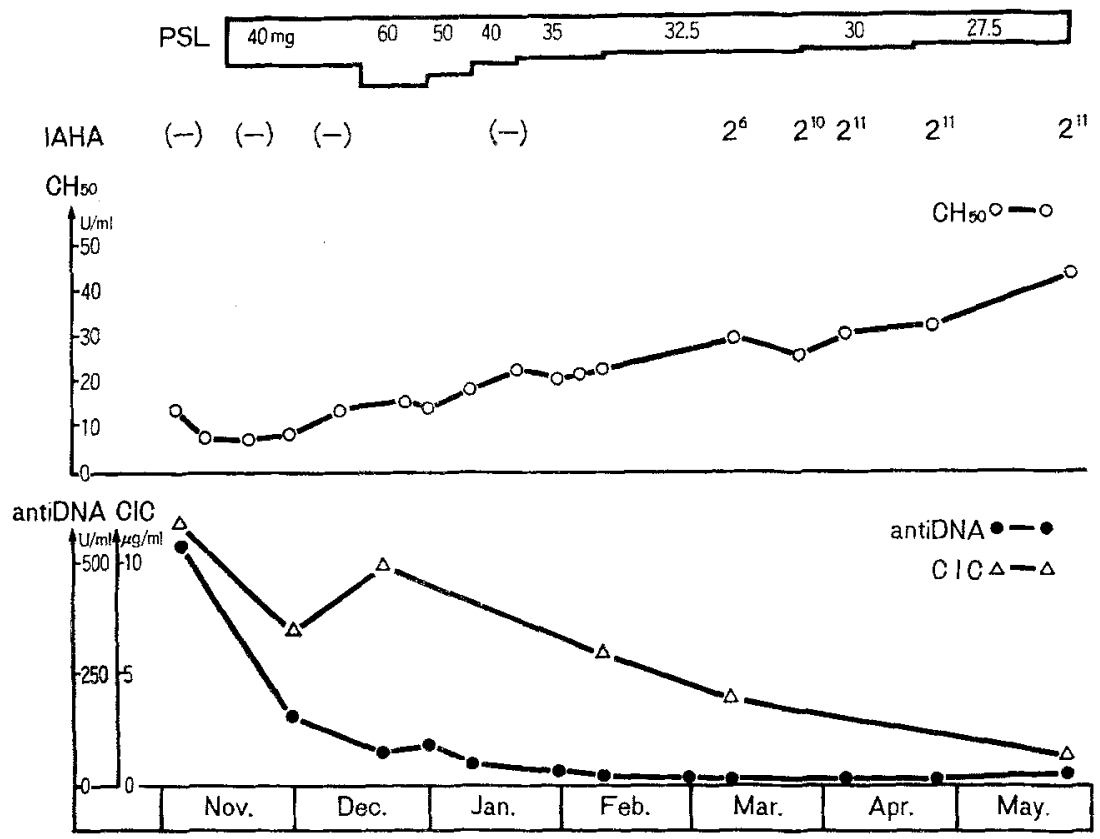

Fig. 4. Clinical course of a 42 y.o. female patient with SLE. 
Relationship between the CRI levels and disease activity

CR1 levels on erythrocytes from 112 SLE patients were followed up for over 26 months. In 22 of the 95 SLE patients who were negative at the initial testing, the CR1 level varied with time during the course of the disease. Figure 4 shows the clinical course of a 42-year-old woman with SLE. CR1 levels in this patient were negative at the beginning of the study, and became positive as she went into the remission while on prednisolone.

\section{DISCUSSION}

As shown in Fig. 1, when CR1 levels among the normal controls were depicted as a frequency histogram, $77(9 \%)$ showed negative IAHA, $558(66 \%)$ had titers ranging $2^{3}$ to $2^{10}$ and $212(25 \%)$ had titers of $2^{11}$. This distribution seemed to be trimodal and suggested the existence of two codominantly expressed alleles that determined high $(\mathrm{H})$ and low (L) levels of CRI originally proposed by Wilson et al. (1982b). Persons with high (211) IAHA titers would be homozygous for the high receptor allele and would have the $\mathrm{HH}$ phenotype, those with negative IAHA would be homozygous for the low allele and would have the LL phenotype, and those with intermediate ( $2^{3}$ to $2^{10}$ ) IAHA titers would be heterozygotes and would have the HL phenotype. However, the expected frequencies of these phenotypes in our

Table 1. Summary of observed phenotypes of a positive and a negative CR1 in 30 families.

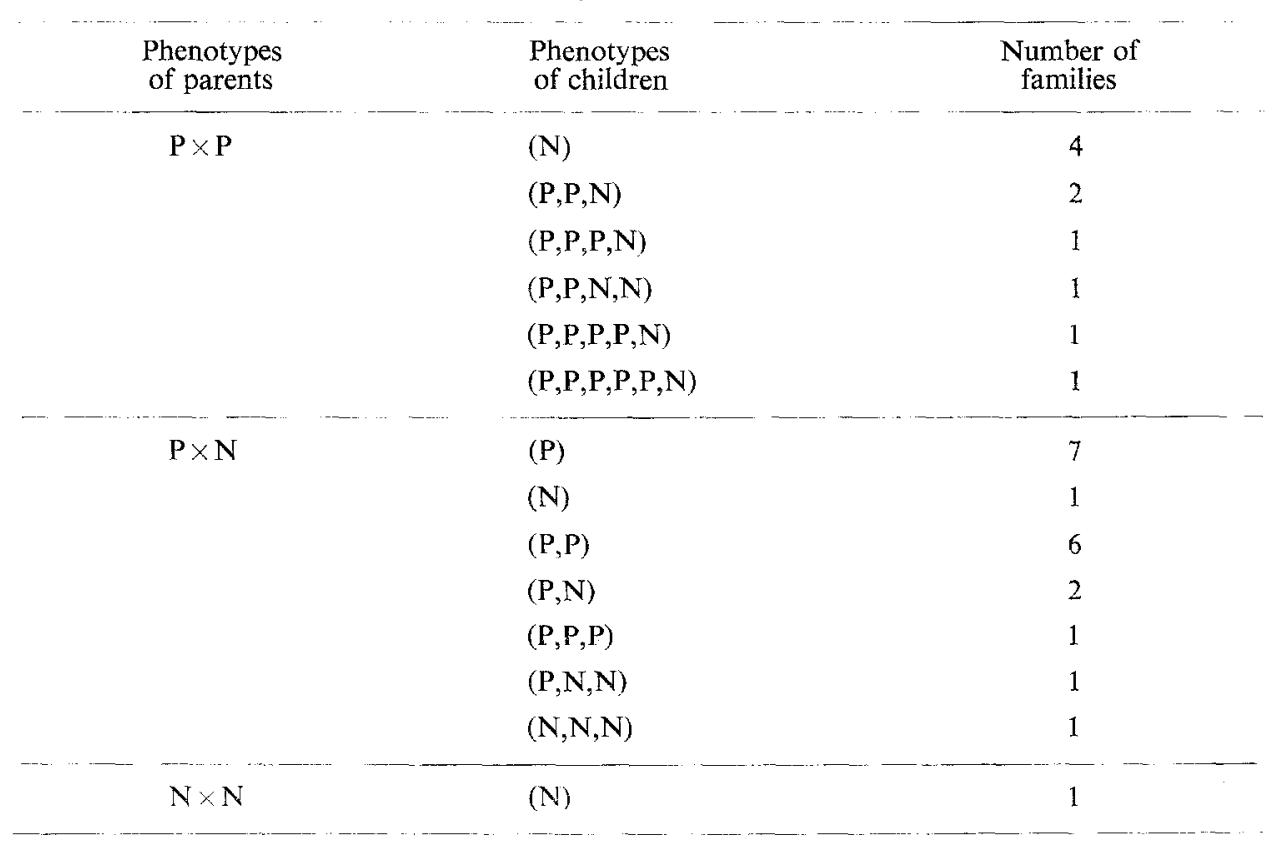

$P$, positive CR1; $\mathrm{N}$, negative CR1. 
Table 2. Tests for goodness of fit of the inheritance of CR1 on the hypotheses of (A) an autosomal recessive inheritance for a positive CR 1 , or (B) and (C) an autosomal recessive inheritance for a negative CR1.

\begin{tabular}{ccccc}
\hline $\begin{array}{l}\text { (A) Backcross }(\mathrm{P} \times \mathrm{N}) \\
\text { Sib size }\end{array}$ & Number of $\mathrm{P}$ & Observed & Expected & $\chi^{2}$ \\
\hline 1 & 1 & 7 & 7 & 0 \\
2 & 1 & 2 & 5.333 & 2.083 \\
2 & 2 & 6 & 2.667 & 4.167 \\
3 & 1 & 1 & 0.857 & 0.024 \\
3 & 2 & 0 & 0.857 & 0.857 \\
3 & 3 & 1 & 0.286 & 1.786 \\
Total & & 17 & 17.000 & 8.917 \\
\hline & & & & \\
\hline (B) Backcross $(\mathrm{P} \times \mathrm{N})$ & & & & \\
Sib size & Number of N & Observed & Expected & $x^{2}$ \\
\hline 1 & 1 & 1 & 1 & 0 \\
2 & 1 & 2 & 1.333 & 0.333 \\
2 & 2 & 0 & 0.667 & 0.667 \\
3 & 1 & 0 & 0.857 & 0.857 \\
3 & 2 & 1 & 0.857 & 0.024 \\
3 & 3 & 1 & 0.286 & 1.786 \\
Total & & 5 & 5.000 & 3.667 \\
\hline
\end{tabular}

(C) Intercross $(\mathbf{P} \times \mathbf{P})$

\begin{tabular}{ccccc} 
Sib size & Number of $N$ & Observed & Expected & $\chi^{2}$ \\
\hline 1 & 1 & 4 & 4 & 0 \\
2 & 1 & 0 & 0 & 0 \\
2 & 2 & 0 & 0 & 0 \\
3 & 1 & 2 & 1.459 & 0.200 \\
3 & 2 & 0 & 0.486 & 0.486 \\
3 & 3 & 0 & 0.054 & 0.054 \\
4 & 1 & 1 & 1.234 & 0.044 \\
4 & 2 & 0.617 & 0.238 \\
4 & 3 & 1 & 0.137 & 0.137 \\
4 & 4 & 0 & 0.011 & 0.011 \\
5 & 1 & 0 & 0.519 & 0.447 \\
5 & 2 & 1 & 0.346 & 0.346 \\
5 & 3 & 0 & 0.115 & 0.115 \\
5 & 4 & 0 & 0.019 & 0.019 \\
5 & 5 & 0 & 0.001 & 0.001 \\
6 & 1 & 0.433 & 0.742 \\
6 & 2 & 0 & 0.361 & 0.361 \\
6 & 3 & 1 & 0.160 & 0.160 \\
6 & 4 & 0 & 0.040 & 0.040 \\
6 & 5 & 0 & 0.005 & 0.005 \\
6 & 6 & 0 & 0.000 & 0.000 \\
Total & & 0 & 9.997 & 3.406
\end{tabular}

(A): (D.F. $=3) p<0.05 . \quad(B):(D . F .=3) p>0.25 . \quad(C):(D . F .=5) p>0.50$. 
normal subjects, as calculated with Hardy-Weinberg equilibrium and assuming this two-codominant-allele model, were 34,49 and $17 \%$ for $\mathrm{HH}, \mathrm{HL}$ and LL phenotypes, respectively, and differed significantly from the observed frequencies. The IAHA method was semi-quantitative and there appeared to be overlaps between high $\left(2^{11}\right)$ and intermediate $\left(2^{3}\right.$ to $\left.2^{10}\right)$ IAHA titers. Even if IAHA titers higher than $2^{8}$ were assumed to be $\mathrm{HH}$ phenotype, there was a significant difference between expected and observed frequencies. Therefore, we considered that $\mathrm{HH}$ and HL phenotypes were indistinguishable by the IAHA method and the frequency histogram of CR1 levels among normal controls showed a bimodal distribution. Segregation of a positive and a negative CR1 among 30 families is summarized in Table 1.

The mode of inheritance for a negative CR1 was analyzed by the maximum likelihood scoring method (Morton, 1959) using informative, 29 normal families. The hypothesis that a positive CR1 is controlled by an autosomal recessive gene should be discarded because many children with negative CRI were segregated from the matings of parents with positive CR1. Moreover, there was a significant difference between observation and expectation $(p<0.05)$ in 17 informative backcross families (Table 2A). Five informative backcross families were then analyzed assuming the hypothesis of an autosomal recessive gene for a negative CR1. There was no significant difference between observation and expectation in segregation of a negative $C R 1$ in these families ( $p>0.25$ ), thereby indicating that the hypothesis of an autosomal recessive gene for a negative CR1 cannot be ignored (Table 2B). The analysis of 10 informative intercross families $(p>0.50)$ (Table $2 C)$ also supports this hypothesis. All these data lend credence to the idea that a negative CRI is of a simple recessive character.

If the results of our studies are compared to those reported by Wilson et al. (1982b), the negative IAHA could correspond to the LL phenotype and the positive IAHA to the HL or HH phenotype. Table 3 shows segregation of the phenotypes in 19 normal families. Data on persons with IAHA titers ranging from $2^{8}$ to $2^{10}$ were ignored because of possible overlaps. Persons with high $\left(2^{11}\right)$, intermediate $\left(2^{3}\right.$ to $2^{7}$ ) and negative IAHA titers were considered to have HH, HL and LL pheno-

Table 3. Segregation of phenotypes for CR1 in 19 families.

\begin{tabular}{|c|c|c|c|c|}
\hline \multirow{2}{*}{$\begin{array}{l}\text { Phenotypes } \\
\text { of parents }\end{array}$} & \multirow{2}{*}{$\begin{array}{l}\text { Number of } \\
\text { families }\end{array}$} & \multicolumn{3}{|c|}{$\begin{array}{l}\text { No of children with } \\
\text { respective phenotypes }\end{array}$} \\
\hline & & $\underset{\left(2^{11}\right)}{\mathrm{HH}}$ & $\underset{\left(2^{3}-2^{7}\right)}{\mathrm{HL}}$ & $\underset{\left(2^{0}\right)}{\mathrm{LL}}$ \\
\hline $\mathbf{H H} \times \mathbf{H L}$ & 2 & 0 & 2 & 0 \\
\hline $\mathbf{H H} \times \mathbf{L L}$ & 1 & 0 & 2 & 0 \\
\hline $\mathbf{H L} \times \mathbf{H L}$ & 5 & 1 & 3 & 5 \\
\hline $\mathrm{HL} \times \mathrm{LL}$ & 10 & 1 & 13 & 7 \\
\hline $\mathrm{LL} \times \mathrm{LL}$ & 1 & 0 & 0 & 1 \\
\hline
\end{tabular}


types. A two codominant allele model of inheritance was supported by this appropriate segregation of the phenotypes. Therefore, there seems to be no contradiction between our data and Wilson's two codominant allele hypothesis.

This study on CRI levels on erythrocytes in SLE patients suggests that a negative CR1 is a simple recessive character as in the normal population. However, the positive CR1 phenotypes in three families were apparently derived from both parents with a negative CR1 (Fig. 3C), a finding incompatible with this hypothesis. In 22 of the 95 SLE patients who had a negative CR1 at the initial testing, the levels became positive during the course of the study. Therefore, the negative CR1 in SLE patients seems to be heterogeneous and acquired factors such as disease activity might contribute to the levels of expression of CR1 molecules on erythrocytes. In over a 2 year follow up, $73(65 \%)$ of the 112 SLE patients, as compared to $77(9 \%)$ of 847 normal controls, showed a persistently negative CR1. Thus, the major factor responsible for the negative CR1 in SLE patients seems to be a genetic one.

Kajiyama (1981) performed an epidemiological study for the purpose of assessing gene-environmental interaction in the development of SLE. He reported that disorders, presumably due to autoimmune mechanisms, hypergammaglobulinemia and unusual immunologic reactions were more frequently found among relatives of SLE patients than in normal individuals and their relatives who served as the controls. Lippman et al. (1982) also investigated genetic factors predisposing to autoimmune disease. Significant differences between relatives and spouses were found in case of occurrence of autoimmune disease, high-titer of antinuclear antibody and antisingle-strand DNA antibody. These observations suggest that genetic rather than environmental factors are more likely to be linked to clinical and serologic differences.

We estimated the relative risk for developing the disease in persons with negative CR1 to be 19, although it was the maximum estimation. CRI on erythrocytes in some cases might be blocked even in a remission. This finding was remarkably high, compared with previously obtained data on HLA antigens and C2 deficiencies that gave the relative risk as between 3 and 6 . Erythrocytes CR 1 deficiency might cause various immunological disorders regarding liberation of free immune complexes into the circulation. Since a negative CR1 was found to be clustered among SLE patients as well as their relatives, this negative CR1 is assumed to be an important genetic factor linked to the development of SLE.

Acknowledgments We thank Prof S. Kashiwagi and Dr. J. Hayashi for arrangements to complete the family study in Okinawa, Miss $Y$. Morinaga for technical assistance, and M. Ohara for critical comments. This work was supported by a Grant-in-Aid for Scientific Research (No. 60570295), a Grant-in-Aid for Encouragement of Classroom Teachers (No. 59770452) from the Ministry of Education, Science and Culture, and a grant from the Ministry of Health and Welfare, Research Committee of Autoimmune Disease.

\section{REFERENCES}

Bianco, C. and Nussenzweig, V. 1977. Complement receptors. Contemp. Top. Mol. Immunol. 6: $145-176$. 
Block, S.R., Winfield, J.B., Lockshin, M.D., D’Angelo, W.A., and Christian, C.L. 1975. Studies of twins with systemic lupus erythematosus. A review of the literature and presentation of 12 additional sets. Am. J. Med. 59: 533-552.

Cornacoff, J.B., Hebert, L.A., Smead, W.L., Vanaman, M.E., Birmingham, D.J., and Waxman, F.J. 1983. Primate erythrocyte-immune complex-clearing mechanims. J. Clin. Invest. 71: 236-247.

Fearon, D.T. 1980. Identification of the membrane glycoprotein that is the $\mathrm{C} 3 \mathrm{~b}$ receptor of the human erythrocyte, polymorphonuclear leukocyte, B lymphocyte and monocyte. J. Exp. Med. 152: 20-30.

Gelfand, M.C., Frank, M.M., and Green, I. 1975. A receptor for the third component of complement in the human renal glomerulus. J. Exp. Med. 142: 1029-1034.

Hahn, B.H. 1987. Animal models of systemic lupus erythematosus. In Dubois' Lupus Erythematosus, Wallace, D.J. and Dubois, E.L., eds., 3rd Ed., Lea \& Febiger, Philadelphia, pp. 130157.

Holme, E., Fyfe, A., Zoma, A., Veitch, J., Hunter, J., and Whaley, K. 1986. Decreased C3b receptors (CR1) on erythrocytes from patients with systemic lupus erythematosus. Clin. exp. Immunol. 63 : 41-48.

Iida, K., Mornaghi, R., and Nussenzweig, V. 1982. Complement receptor (CR1) deficiency in erythrocytes from patients with systemic lupus erythematosus. J. Exp. Med. 155: 1427-1438.

Inada, Y., Kamiyama, M., Kanemitsu, T., Hyman, C.L., and Clark, W.S. 1982. Studies on immune adherence $(\mathrm{C} 3 \mathrm{~b})$ receptor activity of human erythrocytes: relationship between receptor activity and presence of immune complex in serum. Clin. exp. Immunol. 50: 189-197.

Kajiyama, K. 1981. A family study of systemic lupus erythematosus. Fukuoka Acta Medica 72: $102-116$.

Kazatchkine, M.D., Fearon, D.T., Appay, M.D., Mandet, C., and Bariety, J. 1982. Immunohistochemical study of the human glomerular $\mathrm{C} 3 \mathrm{~b}$ receptor in normal kidney and in seventy-five cases of renal diseases. J. Clin. Invest. 69: 900-912.

Lippman, S.M., Arnett, F.C., Conley, C.L., Ness, P.M., Meyers, D.A., and Bias, W.B. 1982. Genetic factors predisposing to autoimmune diseases. Autoimmune hemolytic anemia, chronic thrombocytopenic purpura and systemic lupus erythematosus. Am. J. Med. 73: $827-840$.

Mayumi, M., Okochi, K., and Nishioka, K. 1971. Detection of Australia antigen by means of immune adherence haemagglutination test. Vox Sang. 20: 178-181.

Miyakawa, Y., Yamada, A., Kosaka, K., Tsuda, F., Kosugi, E., and Mayumi, M. 1981. Defective immune-adherence $(\mathrm{C} 3 \mathrm{~b})$ receptor on erythrocytes from patients with systemic lupus erythematosus. Lancet II: $493-497$.

Morton, N.E. 1959. Genetic tests under incomplete ascertainment. Am. J. Hum. Genet. 11: 1-16.

Ross, G.D. 1979. Identification of human lymphocyte subpopulations by surface marker analysis. Blood 53: 799-811.

Siegel, I., Liu, T.L., and Gleicher, N. 1981. The red-cell immune system. Lancet II: 556-559.

Tan, E.M., Cohen, A.S., Fries, J.F., Masi, A.T., Mcshane, D.J., Rothfield, M.F., Schaller, J.G., Talal, N., and Winchester, R.J. 1982. The 1982 revised criteria for the classification of systemic lupus erythematosus. Arthritis Rheum. 25: 1271-1277.

Wilson, J.G., Tedder, T.F., and Fearon, D.T. 1982a. Antigenic and functional detection of C3b receptors on human peripheral blood T-lymphocytes. Fed. Proc. 41: 965.

Wilson, J.G., Wong, W.W., Schur, P.H., and Fearon, D.T. 1982b. Mode of inheritance of decreased $\mathrm{C} 3 \mathrm{~b}$ receptors on erythrocytes of patients with systemic lupus erythematosus. $N$. Engl. J. Med. 307: 981-986. 